\title{
Comparison of TNF- $\alpha$ and IL-1 $\beta$ Concentrations in Gingival Crevicular Fluid During Early Alignment Stage of Orthodontic Treatment in Adults and Adolescents
}

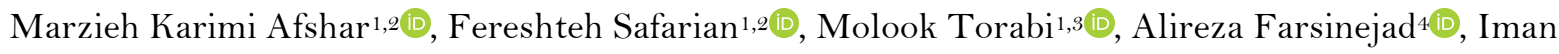 \\ Mohammadzadeh ${ }^{5}$ (1)
}

\begin{abstract}
${ }^{1}$ Kerman Social Determinants on Oral Health Research Center, Kerman University of Medical Sciences, Kerman, Iran. ${ }^{2}$ Department of Orthodontics, School of Dentistry, Kerman University of Medical Sciences, Kerman, Iran. ${ }^{3}$ Department of Oral Pathology, School of Dentistry, Kerman University of Medical Sciences, Kerman, Iran. ${ }^{4}$ Physiology Research Center, Institute of Basic and Clinical Physiology Sciences, Kerman University of Medical Sciences, Kerman, Iran.

${ }^{5}$ Oral and Dental Diseases Research Center, Kerman University of Medical Science, Kerman, Iran.
\end{abstract}

Author to whom correspondence should be addressed: Molook Torabi, Department of Oral Pathology, School of Dentistry, Kerman University of Medical Sciences, Shafa Ave, Jomhoori Islami BLVD, Kerman 7618759689, Iran. Phone: +989131415238. E-mail: m.torabi.p@gmail.com.

Academic Editors: Alessandro Leite Cavalcanti and Wilton Wilney Nascimento Padilha

Received: 04 February 2020 / Accepted: 30 April 2020 / Published: 20 May 2020

How to cite this article: Afshar MK, Safarian F, Torabi M, Farsinejad A, Mohammadzadeh I. Comparison of TNF- $\alpha$ and IL-1 $\beta$ concentrations in gingival crevicular fluid during early alignment stage of orthodontic treatment in adults and adolescents. Pesqui Bras Odontopediatria Clín Integr. 2020; 20:e0004. https://doi.org/10.1590/pboci.2020.086

\begin{abstract}
Objective: To compare the levels of TNF- $\alpha$ and IL- $1 \beta$ in the gingival crevicular fluid (GCF) during early leveling stage of orthodontic treatment. Material and Methods: This study was carried out on 20 orthodontic patients, including 10 teenagers and 10 adults. Before bonding, GCF was collected with a paper strip in gingival sulcus of maxillary right central incisor on the disto labial aspect for 60 seconds, followed by bonding and insertion of initial $14 \mathrm{NiTi}$ archwire. GCF collection was repeated 24 hours, 7 days, and 28 days after bonding. Measurement of TNF- $\alpha$ and IL-1 $\beta$ levels was done utilizing Enzyme-Linked Immunosorbent Assay (ELISA). Data were analyzed in SPSS using repeated measurement test. Results: Concentration of TNF- $\alpha$ and IL- $1 \beta$ increased after treatment. There was no significant relationship between TNF- $\alpha$ and IL-1 $\beta$ concentrations subsequent to bonding in comparison to the baseline. There was no significant relationship in TNF- $\alpha$ and IL- $1 \beta$ level changes in the two age groups and between males and females. Conclusion: Concentration of TNF- $\alpha$ and IL-1 $\beta$ increased after treatment. Age and sex had no statically significant effect on the concentration of TNF- $\alpha$ and IL- $1 \beta$.
\end{abstract}

Keywords: Orthodontics; Tooth Movement Techniques; Cytokines; Gingival Crevicular Fluid. 


\section{Introduction}

It is widely accepted that the application of force to the teeth and its adjacent structures induces changes in the gingiva, periodontium, cementum, and alveolar bone, as well as cellular population and remodeling capacity. Tooth movement is a complex process requiring modification of the gingiva, PDL, tooth cementum, and alveolar bone [1].

During orthodontic treatment, early periodontal tissue responses to mechanical stress include different metabolic changes that provide for tooth movement. Successful orthodontic movement of the teeth requires periodontium remodeling, especially of the alveolar bone. When little force is applied for a long period, inflammatory responses initiate that result in bone resorption and tooth movement [2]. Mechanical stress caused by orthodontic appliances stimulates the cells in the periodontium to produce bioactive substances such as cytokines and enzymes responsible for the remodeling of connective tissues and osteoclast activation. These substances can be evaluated non-invasively by keeping track of the changes that occur in the gingival crevicular fluid $(\mathrm{GCF})$ in tooth movement [3]. Bone remodeling during tooth movement is a biological process that involves the chronic inflammatory response of the periodontal tissue [4]. Orthodontic tooth movement entails a number of inflammation-like reactions, including excessive vascular activity, increased leukocyte and macrophage count, as well as, immune system involvement. Cytokines such as IL, RANKL, and TNFs and, also, interferons and growth factors play a significant role in regulating the turnover in connective tissues and bone remodeling during tooth movement.

Cytokines are referred to as proteins produced by certain cells (mainly active lymphocytes and macrophages) to regulate the function of other cells [5]. In the pathology of periodontal diseases, these proteins have a role in bone destruction and bone response to orthodontic treatment, and their main involvement is in bone remodeling.

Cytokines are associated with alveolar bone and periodontal cell activity since early tooth movement requires inflammatory reactions related to leukocyte migration [3,5,6]. They also play a part in the migration of monocytes to PDL, where they are transformed into osteoclasts and macrophages and are vital to orthodontic movement $[6,7]$.

The fact is that IL-1, IL-6, and TNF- $\alpha$ are pre-inflammatory cytokines involved in bone remodeling, bone resorption, and new bone deposition [8]. IL-1 and TNF are the two main cytokines and inflammatory mediums, primarily produced and activated by macrophages, and largely involved in inflammation, the effects on the endothelium, leukocytes, and fibroblasts, and also, the induction of systemic chronic-phase reactions [5].

It has been shown that the orthodontic forces cause a rapid release of TNF- $\alpha$, IL- $1 \beta$, and IL- 8 in the process of tooth movement, the increase of which is clearly visible in GCF [9]. In an other study carried out on 18 orthodontic patients of 16 to 19 years of age, the authors discovered that increases in TNF- $\alpha$ and IL- $1 \beta$ in periodontal tissues resulting from leveling and distalization techniques during orthodontic treatment can also be distinguished in GCF [10]. Meantime, it was still observed an increase in SP and IL-1 $\beta$ levels during tooth movement in adults, with a possible role in triggering periodontal inflammation in response to mechanical stress [11]. On the other hand, previous authors reported an increase in IL-1 $\beta$ and IL-8 after orthodontic appliance and expressed it as a possible biological activity of the periodontium during tooth movement [12]. 
Although orthodontic treatment in adults is fundamentally similar to adolescents in terms of goals, stages and tissue changes relating to tooth movement, there are certain biological differences - such as the adult bone being less responsive to mechanical forces, higher risk of attachment loss and marginal bone resorption, as well as a slower tissue remodeling - that result in the slower rate of tooth movement and an elongated period of treatment in adults. At the same time, tooth movement occurs later in adults when compared to adolescents [13].

The aim of this study was to compare the Levels of TNF- $\alpha$ and IL-1 $\beta$ in gingival crevicular fluid (GCF) during early treatment alignment of adult and adolescent orthodontic patients in the orthodontics Department of Dental School Kerman, Iran.

\section{Material and Methods}

\section{Study Design and Sample}

This descriptive-analytical study was carried out on 20 orthodontic patients referring to specialized orthodontic centers in the City of Kerman. Cases included 10 teenage patients 12- to 19 years and 10 adult patients 20-33 years old.

Inclusion criteria were as follows: satisfactory general health, absence of antibiotic consumption in the 6 months leading to the time of study, absence of anti-inflammatory medication in the month leading to the time of study, absence of periodontal disease (probe depth of $\leq 3 \mathrm{~mm}$ with no attachment loss, and radiographic indications of bone resorption), Class 1 malocclusion, incisor irregularity index of 3-6 mm, possessing permanent dentition and absence of teeth removal in the treatment plan.

\section{Data Collection}

Patients were selected and briefed about the objectives of the study before obtaining their consent. Data related to age and sex were recorded in a checklist. Plaque removal and brushing were applied to all patients one week before bonding and patients were advised about oral health tips. Before applying orthodontic treatment, tooth surface was dried with compressed air and isolated employing cotton roll. GCF was collected prior to further examination. Paper strip (Periopaper, Medical Electronic Devices Inc., Tustin, CA, USA) was placed for 60 seconds inside the gingival sulcus, 1-2 mm beneath the gingival margin of maxillary central incisor on the disto labial aspect, followed by bonding with bracket system MBT 0.022 slot and insertion of initial 14 NiTi archwire (Ortho Technology Inc., Tampa, FL, USA). Patients were resummoned 24 hours, 7 days, and 28 days after the onset of treatment and GCF samples were recollected in the manner described above $[3,10,11]$. Strips contaminated with blood and/or saliva were excluded from the study. Paper strips were, then, placed in a sterile tube and despatched to the Lab, where they were stored at $-20^{\circ} \mathrm{C}$ till the day of study. For all patients, GCF was collected in the afternoons between 4:00-5:00 p.m. Enzyme-Linked Immunosorbent Assay (ELISA) was used to measure TNF- $\alpha$ and IL-1. UK Abcam ${ }^{\circledR}$ ab46052 and ab46088 (Abcam plc, Cambridge, UK) were used to measure IL-1 and for TNF- $\alpha$, respectively. Samples were prepared as instructed in the company manual. Concentration levels of prepared samples were compared to TNF- $\alpha$ and IL-1 standards. The concentration of biomarkers $(\mathrm{pg} / \mathrm{mL})$ was measured with model ELx 808 microplate reader (BioTek Instruments Inc., Winooski, VT, USA).

Data Analysis 
Collected data was registered in checklist and fed to a computer for further analysis utilizing SPSS, version 20 (IBM SPSS Inc., Chicago, IL, USA). Advanced Statistical Software, using repeated measurement test at a significance level of 0.05 .

\section{Ethical Aspects}

This research was approved with the Code of K/93/07 by the Ethics Committee of Kerman University of Medical Sciences. The participants were assured that their name would not be mentioned in any part of the research and that the participation in the project is entirely voluntary and with full consent. Patients under 18 years of age were required to submit a parental letter of consent before their participation.

\section{Results}

Ten individual participants (50\%) were under 19 and 10 others (50\%) were above 19 years of age with a minimum and maximum age of 12 and 33, respectively, and a median age of $19.11 \pm 6.33$. Thirteen of the cases $(65 \%)$ were female and 7 (35\%) were male participants.

The results show an increase in IL-1 concentration in different post-treatment time intervals as compared to baseline. At the same time, TNF- $\alpha$ mean concentration level increases over all post-treatment time intervals, reaching a peak value within a week. Altogether, there is no significant statistical difference between baseline and post-treatment TNF- $\alpha$ and IL-1 concentrations (Table 1).

Table 1. Correlation between concentration of IL1- $\beta$ and TNF $\alpha$ at baseline and treatment interval.

\begin{tabular}{clccc}
\hline \multicolumn{1}{c}{ Variables } & \multicolumn{1}{c}{ Treatment Time } & Mean & SD & p-value \\
\hline IL1- $\beta$ & Baseline & 14.17 & 6.48 & 0.32 \\
& 1 Day After Treatment & 17.63 & 9.01 & \\
1 Week After Treatment & 15.13 & 10.40 & \\
TNF $\alpha$ & 4 Weeks After Treatment & 18.14 & 9.30 & 0.38 \\
& Baseline & 38.84 & 4.51 & \\
& 1 Day After Treatment & 38.92 & 2.66 & \\
& 1 Week After Treatment & 42.28 & 10.09 & \\
& 4 Weeks After Treatment & 39.63 & 5.91 & \\
\hline
\end{tabular}

Table 2 illustrates the mean concentration of IL-1 $\beta(\mathrm{pg} / \mathrm{mL})$ for gender and age groups. No meaningful difference was observed for different age groups and genders in terms of IL-1 $\beta$ concentration levels across different post-treatment time intervals.

Table 2. Correlation between IL1- $\beta$ concentration with gender and age.

\begin{tabular}{|c|c|c|c|c|c|}
\hline \multirow[b]{2}{*}{ Gender } & \multicolumn{4}{|c|}{ Treatment Time } & \multirow[b]{2}{*}{ p-value } \\
\hline & $\begin{array}{c}\text { Baseline } \\
\text { Mean (SD) }\end{array}$ & $\begin{array}{c}1 \text { Day } \\
\text { Mean (SD) }\end{array}$ & $\begin{array}{c}1 \text { Week } \\
\text { Mean (SD) }\end{array}$ & $\begin{array}{c}\text { 4. Weeks } \\
\text { Mean (SD) }\end{array}$ & \\
\hline \multicolumn{6}{|l|}{ Male } \\
\hline$<19$ years old & $14.21 \pm 7.67$ & $19.27 \pm 8.04$ & $10.29 \pm 3.95$ & $18.76 \pm 15.73$ & $>0.05$ \\
\hline$\geq 19$ years old & $7.21 \pm 1.88$ & $8.94 \pm 2.75$ & $11.47 \pm 5.57$ & $19.37 \pm 3.46$ & $>0.05$ \\
\hline Total & $12.46 \pm 6.65$ & $15.25 \pm 8.85$ & $10.69 \pm 3.93$ & $18.97 \pm 12.28$ & \\
\hline \multicolumn{6}{|l|}{ Female } \\
\hline$<19$ years old & $13.31 \pm 5.48$ & $18.29 \pm 10.90$ & $20.95 \pm 16.70$ & $15.37 \pm 9.46$ & $>0.05$ \\
\hline$\geq 19$ years old & $16.39 \pm 7.41$ & $19.12 \pm 8.40$ & $13.94 \pm 4.88$ & $19.80 \pm 6.89$ & $>0.05$ \\
\hline Total & $14.97 \pm 6.52$ & $18.74 \pm 9.22$ & $17.18 \pm 11.98$ & $17.76 \pm 8.15$ & \\
\hline
\end{tabular}


Mean TNF- $\alpha$ for age groups and genders is shown in Table 3. Again, no meaningful difference is observed for different age groups and genders in terms of $\mathrm{TNF}-\alpha$ concentration level across different posttreatment time intervals.

Table 3. Mean of TNF- $\alpha$ concentration based on participants' gender and age.

\begin{tabular}{|c|c|c|c|c|c|}
\hline \multirow[b]{2}{*}{ Gender } & \multicolumn{4}{|c|}{ Treatment Time } & \multirow[b]{2}{*}{ p-value } \\
\hline & $\begin{array}{c}\text { Baseline } \\
\text { Mean (SD) }\end{array}$ & $\begin{array}{c}1 \text { Day } \\
\text { Mean (SD) }\end{array}$ & $\begin{array}{c}1 \text { Week } \\
\text { Mean (SD) }\end{array}$ & $\begin{array}{c}4 \text { Weeks } \\
\text { Mean (SD) }\end{array}$ & \\
\hline \multicolumn{6}{|l|}{ Male } \\
\hline$<19$ years old & $37.55 \pm 4.57$ & $39.23 \pm 2.14$ & $51.44 \pm 19.53$ & $36.06 \pm 3.03$ & $>0.05$ \\
\hline$\geq 19$ years old & $39.81 \pm 1.20$ & $42.25 \pm 8.71$ & $41.64 \pm 2.18$ & $34.77 \pm 1.44$ & $>0.05$ \\
\hline Total & $39.12 \pm 5.79$ & $39.43 \pm 1.76$ & $48.17 \pm 15.98$ & $35.63 \pm 2.52$ & \\
\hline \multicolumn{6}{|l|}{ Female } \\
\hline$<19$ years old & $38.93 \pm 3.08$ & $40.52 \pm 4.67$ & $38.44 \pm 4.20$ & $41.61 \pm 4.03$ & $>0.05$ \\
\hline$\geq 19$ years old & $37.17 \pm 2.96$ & $38.48 \pm 3.20$ & $40.52 \pm 4.98$ & $41.37 \pm 7.91$ & $>0.05$ \\
\hline Total & $38.69 \pm 4.04$ & $38.72 \pm 3.02$ & $39.56 \pm 4.57$ & $41.48 \pm 6.17$ & \\
\hline
\end{tabular}

Biomarker $\beta$ IL-1 and TNF- $\alpha$ concentrations for two both gender groups over different time intervals are compared in Table 4. No meaningful difference exists between the two groups prior to treatment and during treatment.

Table 4. Differences between TNF- $\alpha$ and IL-1 $\beta$ in genders and treatments interval.

\begin{tabular}{|c|c|c|c|c|c|}
\hline \multirow{2}{*}{ Gender } & \multicolumn{4}{|c|}{ Treatment Time } & \multirow[b]{2}{*}{ p-value } \\
\hline & $\begin{array}{c}\text { Baseline } \\
\text { Mean }(\mathrm{SD})\end{array}$ & $\begin{array}{c}1 \text { Day } \\
\text { Mean (SD) }\end{array}$ & $\begin{array}{c}1 \text { Week } \\
\text { Mean (SD) }\end{array}$ & $\begin{array}{c}\text { 4. Weeks } \\
\text { Mean (SD) }\end{array}$ & \\
\hline \multicolumn{6}{|l|}{ Male } \\
\hline$<19$ years old & $15.25 \pm 8.85$ & $12.46 \pm 6.65$ & $10.69 \pm 3.93$ & $18.97 \pm 12.28$ & 0.34 \\
\hline $\begin{array}{l}\quad \geq 19 \text { years old } \\
\text { Female }\end{array}$ & $18.74 \pm 9.22$ & $14.97 \pm 6.52$ & $17.18 \pm 11.98$ & $17.76 \pm 8.15$ & \\
\hline$<19$ years old & $39.12 \pm 5.79$ & $39.43 \pm 1.76$ & $48.17 \pm 15.98$ & $35.63 \pm 2.52$ & 0.72 \\
\hline$\geq 19$ years old & $37.72 \pm 4.04$ & $38.69 \pm \mathrm{v}$ & $39.56 \pm 4.57$ & $41.48 \pm 6.17$ & \\
\hline
\end{tabular}

\section{Discussion}

Orthodontic tooth movement is an inflammatory process associated with periodontal and oral tissue mechanical responses that are vital for tooth movement under clinical conditions. The initial effects of orthodontic forces are physical and biological in nature [14]. In this study, gingival crevicular fluid (GCF) is used to measure TNF- $\alpha$ and IL-1 concentrations. Similar studies have proved GCF to be an efficient and noninvasive factor for such measurements [12,15-17].

Gingival crevicular fluid exudate is an exclusive tool for studying mediators. With an acceptable level of sensitivity and the capability to be repeated in different phases of orthodontic treatment, it can take the course of the supervision stage [18].

In the present study, the mean concentration of IL-1 $\beta$ in different time intervals of treatment increased as compared to baseline. The result closely matches that obtained by other authors, where a posttreatment IL-1 $\beta$ concentration increase was reported [10]. In the study carried out by Italian researchers, IL$1 \beta$ concentration in the area of applied force shows an increase during tooth movement [19]. Some researchers showed that levels of IL-1 $\beta$ increased in the root resorption area in tooth movements of treated rats [20] 
IL-1 $\beta$ is a strong cytokine of the periodontal environment in the course of tooth movement [21]. By comparing IL-1, IL-4, and IL-8 concentration in the GCF of children and adolescents with and without fixed orthodontic treatment, it has been shown that fixed orthodontic appliances cause an increase in the aforementioned cytokines [12].

The present research shows no meaningful statistical difference in the mean IL-1 concentration value at baseline as compared to that in the different time intervals, similar to that previously demonstrated (10,21). Meantime, some authors studied IL-1 concentration in GCF in 1, 4, 8, 24, 72, 120, and 168-hour posttreatment time intervals and demonstrated how it reaches its maximum value at the 24-hour time interval, as similarly observed in the current research [11]. In the present investigation, there is an increase in the TNF- $\alpha$ concentration at every post-treatment time interval vs. baseline. Despite of not being statistically meaningful, the increase corresponds to the findings observed previously [10,22]. Additionally, the authors found no significant increase in IL- 1 and $\mathrm{TNF}-\alpha$ concentrations at different time intervals of the fixed orthodontic posttreatment period [10,22]. According to the previous results, IL-1 and TNF- $\alpha$ concentrations reach a maximum value in the initial 24-hour time interval [23]. Other authors also report a similar increase in TNF$\alpha$ in the initial 24-hour time interval vs. baseline [24,25]. It was also revealed that concentration of TNF- $\alpha$ in force area was higher than the control side [26]. TNF- $\alpha$ is expressed in the force-applied area of the tooth and has a significant role in mechanical tooth movement [27]. Orthodontic tooth movement increases TNF- $\alpha$ in the area surrounding the periodontal tissue [26].

It has been shown that a tooth-movement induced an increase in the population of TNF- $\alpha$ positive cells in the 1, 4, 7, and 10 days intervals for two varying treatment models [28]. In this study, no meaningful statistical difference was observed in the TNF- $\alpha$ and IL-1 concentrations of under 19 vs. plus 19 age groups at any given time interval, and these results are similar to those reported by other authors [3]. At the same time, an increase in GM-CSF and IL-6 has been reported only in the adolescent group [29].

The absence of a meaningful statistical difference in the 2 age groups studied in this research may be due to the mean age of the individuals concerned. In other words, the results may vary with a rise in the population of young adults. An equal force was applied to the teeth during treatment to prevent the force factor from causing changes in cytokine concentrations at different post-treatment intervals. It was shown that the IL-1 concentration to increases in the initial 24-hour interval and returns to a stable state in groups receiving continuous and continual force [21]. Meantime, some authors report no increase in TNF- $\alpha$ and IL-1 cytokines resulting from larger forces [30].

No meaningful statistical difference was observed, in the present study, between gender and mean concentration of different biomarkers involved. In most similar studies, the effect of gender on TNF- $\alpha$ and IL-1 values has not been considered. A previous study showed that gender has no role in increasing enzymatic activity [31].

A finding that corresponds to the present study, where no meaningful statistical difference is reported between gender and TNF- $\alpha$ and IL-1 mean concentration. One of the limitations of the present study was low sample size. It was due to the uniformity of orthodontic treatment.

\section{Conclusion}

According to the findings of this study, TNF- $\alpha$ and IL-1 in the gingival crevicular fluid increase by fixed orthodontic treatment compared to the period prior to treatment. No meaningful statistical difference 
was observed in TNF- $\alpha$ and IL-1 concentrations at varying post-treatment intervals vs. the pre-treatment period for different adult and adolescent age groups. It is recommended that studies focus on individuals with a higher age average and different treatments.

\section{Authors' Contributions}

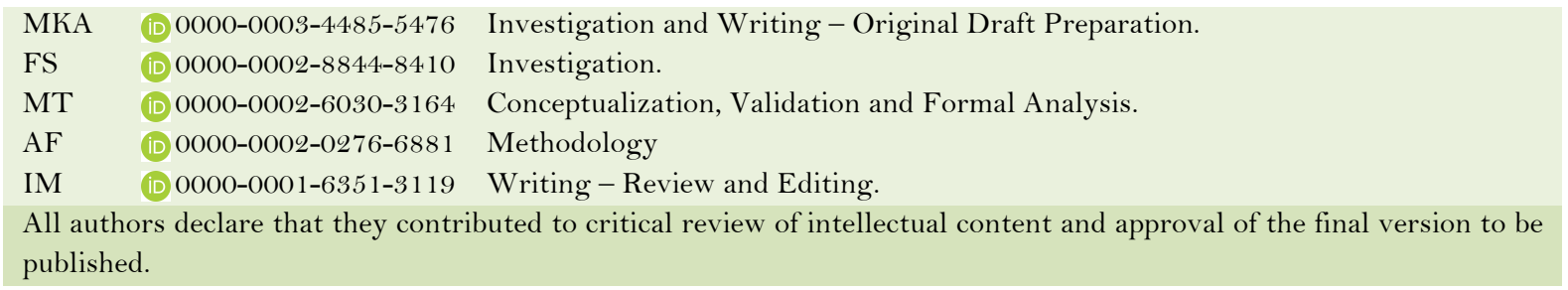

\section{Financial Support}

None.

\section{Conflict of Interest}

The authors declare no conflicts of interest.

\section{Acknowledgments}

The authors hereby would like to thank and appreciate all the patients who participated in this research and the Deputy of Research and Technology at the Kerman University of Medical Sciences to approve the project.

\section{References}

[1] Thailander B. Tissue Reactions in Orthodontics. In: Graber WL, Vanarsdall RL, Vig K. Orthontics Current Principles and Techniques. 5th ed. Philadelphia: Elsevier Mosby 2012; Chapter 9: pp. 247-248, 261, 273.

[2] Meeran AN. The role of gingival crevicular fluid in orthodontic tooth movement - a review. J Dent Sci 2011; 2:12933.

[3] Rody WJ, Wijegunasinghe M, Wiltshire WA, Dufault B. Differences in the gingival crevicular fluid composition between adults and adolescents undergoing orthodontic treatment. Angle Orthod 2014; 84(1):120-6. https://doi.org/10.2319/012813-85.1

[4] Roberts WE. Bone Physiology, Metabolism, and Biomechanics in Orthodontics Practice. In: Graber WL, Vanarsdall RL, Vig K. Orthontics Current Principles and Techniques. 5th ed. Philadelphia: Elsevier Mosby; 2012.

[5] Kumar V, Abbas AK, Fausto N. Robbins and Cotran Pathologic Basis of Disease. 7th ed. Philadelphia: Elsevier Saunders; 2005.

[6] Tuncer BB, Ozmeric N, Tuncer C, Teoman I, Cakılcıb B, Yucel A, et al. Levels of interleukin-8 during tooth movement. Angle Orthod 2005; 75(4):631-6.

[7] Capelli Junior J, Kantarci A, Haffajee A, Teles RP, Fidel Jr R, Figueredo CM. Matrix metalloproteinases and chemokines in the gingival crevicular fluid during orthodontic tooth movement. Eur J Orthod 2011; 33(6):705-11. https://doi.org/10.1093/ejo/cjq148

[8] Alhashimi N, Frithiof L, Brudvik P, Bakhiet M. Orthodontic tooth movement and de novo synthesis of proinflammatory cytokines. Am J Orthod Dentofacial Orthop 2001; 119(3):307-12. https://doi.org/10.1067/mod.2001.110809

[9] Acun Kaya F, Hamamchi N, Basaran G, Dogru M, Talo Yildrim T. TNF- $\alpha$, IL-1 $\beta$ and IL-8 levels in tooth early leveling movement orthodontic treatment. J Int Dent Med Res 2010; 3(3):116-21.

[10] Basaran G, Ozer T, Kaya FA, Kaplan A, Hamamci O. Interleukine-1 $\beta$ and Tumor Necrosis Factor- $\alpha$ levels in the human gingival sulcus during orthodontic treatment. Angle Orthod 2006; 76(5):830-6.

[11] Yamaguchi M, Yoshii M, Kasai K. Relationship between substance P and interleukin-1B in gingival crevicular fluid during orthodontic tooth movement in adults. Eur J Orthod 2006; 28(3):241-6.

[12] Giannopoulou C, Mombelli A, Tsinidou K, Vasdekis V, Kamma J. Detection of gingival crevicular fluid cytokines in children and adolescents with and without fixed orthodontic appliances. Acta Odontol Scand 2008; 66(3):169-73. https://doi.org/10.1080/00016350802123126 
[13] Bagga D.K. Adult orthodontics versus adolescent orthodontics: an overview. J Oral Health Comm Dent 2010; $4(2): 42-7$.

[14] Di Domenico M, D'apuzzo F, Feola A, Cito L, Monsurrò A, Pierantoni GM, et al. Cytokines and VEGF induction in orthodontic movement in animal models. J Biomed Biotechnol 2012; 2012:201689. https://doi.org/10.1155/2012/201689

[15] Ribagin LS, Rashkova MR. Matrix metalloproteinase-8 and interleukin-1beta in gingival fluid of children in the first three months of orthodontic treatment with fixed appliances. Folia Med 2012; 54(3):50-6.

[16] Barbieri G, Solano P, Alarcón JA, Vernal R, Rios-Lugo J, Sanz M, Martín C. Biochemical markers of bone metabolism in gingival crevicular fluid during early orthodontic tooth movement. Angle Orthod 2013; 83(1):63-9. https://doi.org/10.2319/022812-168.1

[17] Hamamcı N, Kaya FA, Uysal E, Yokuş B. Identification of interleukin 2, 6, and 8 levels around miniscrews during orthodontic tooth movement. Eur J Orthod 2012; 34:357-61. https://doi.org/10.1093/ejo/cjro19

[18] Kapoor P, Kharbanda OP, Monga N, Miglani R, Kapila S. Effect of orthodontic forces on cytokine and receptor levels in gingival crevicular fluid: a systematic review. Prog Orthod 2014; 15:65.

https://doi.org/10.1186/s40510-014-0065-6

[19] Castroflorio T, Gamerro EF, Caviglia GP, Deregibus A. Biochemical markers of bone metabolism during early orthodontic tooth movement with aligners. Angle Orthod 2017; 87(1):74-81. https://doi.org/10.2319/022416-159.1

[20] Matsumoto Y, Sringkarnboriboon S, Ono T. Proinflammatory mediators related to orthodontically induced periapical root resorption in rat mandibular molars. Eur J Orthod 2017; 39(6):686-91. https://doi.org/10.1093/ejo/cjx033

[21] Lee KJ, Park YC, Yu HS, Choi SH, Yoo YJ. Effects of continuous and interrupted orthodontic force on interleukin-1 $\beta$ and prostaglandin E2 production in gingival crevicular fluid. Am J Orthod Dentofacial Orthop 2004; 125(2):168-77. https://doi.org/10.1016/j.ajodo.2003.03.006

[22] MacLaine JK, Rabie ABM, Wong R. Does orthodontic tooth movement cause an elevation in systemic inflammatory markers? Eur J Orthod 2010; 32:435-40. https://doi.org/10.1093/ejo/cjp108

[23] Ren Y, Hazemeijer H, de Haan B, Qu N, de Vos P. Cytokine profiles in crevicular fluid during orthodontic tooth movement of short and long durations. J Periodontol 2007; 78(3):453-8.

[24] Chami VO, Nunes L, Capelli Júnior J. Expression of cytokines in gingival crevicular fluid associated with tooth movement induced by aligners: a pilot study. Dental Press J Orthod 2018; 23(5):41-6. https://doi.org/10.1590/2177-6709.23.5.041-046.oar

[25] Jayaprakash PK, Basavanna JM, Grewal H, Modi P, Sapawat P, Bohara PD. Elevated levels of Interleukin (IL)-1 $\beta$, IL-6, tumor necrosis factor- $\alpha$, epidermal growth factor, and $\beta 2$-microglobulin levels in gingival crevicular fluid during human Orthodontic tooth movement (OTM). J Family Med Prim Care 2019; 8:1602-6. https://doi.org/10.4103/jfmpc.jfmpc_204_19

[26] Padisar P, Hashemi R, Naseh M, Nikfarjam BA, Mohammadi M. Assessment of tumor necrosis factor alpha $(\mathrm{TNF} \alpha)$ and interleukin 6 level in gingival crevicular fluid during orthodontic tooth movement: a randomized splitmouth clinical trial. Electron Physician 2018; 10(8):7146-54. https://doi.org/10.19082/7146

[27] Kitaura H, Kimura K, Ishida M, Sugisawa H, Kohara H, Yoshimatsu M, et al. Effect of cytokines on osteoclast formation and bone resorption during mechanical force loading of the periodontal membrane. Sci World J 2014; 2014:617032. https://doi.org/10.1155/2014/617032

[28] Sugimori T, Yamaguchi M, Shimizu M, Kikuta J, Hikida T, Hikida M. Micro-osteoperforations accelerate orthodontic tooth movement by stimulating periodontal ligament cell cycles. Am J Orthod Dentofacial Orthop 2018; 154(6):78896. https://doi.org/10.1016/j.ajodo.2018.01.023

[29] Ren Y, Maltha JC, Van't Hof MA, Von den Hoff JW, Kuijpers-Jagtman A, Zhang D. Cytokine levels in crevicular fluid are less responsive to orthodontic force in adults than in juveniles. J Clin Periodontol 2002; 29(8):757-62. https://doi.org/10.1034/j.1600-051x.2002.290813.x

[30] Alikhani M, Alyami B, Lee IS, Almoammar S, Vongthongleur T, Alikhani M, et al. Saturation of the biological response to orthodontic forces and its effect on the rate of tooth movement. Orthod Craniofac Res 2015; 18(Suppl 1):8-17. https://doi.org/10.1111/ocr.12090

[31] Serra E, Perinetti G, D' Attillo M, Cordella C, Poalantani M, Festa F, et al. Lactate dehydrogenase activity in gingival crevicular fluid during orthodontic treatment. Am J Orthod Dentofacial Orthop 2003; 124(2):206-11. https://doi.org/10.1016/s0889-5406(03)00407-4 